\title{
MORBIDITY PATTERN AND HEALTH-SEEKING BEHAVIOUR AMONG THE SENIOR CITIZENS IN SELECTED RURAL AREAS OF BANGLADESH
}

\author{
JABEEN $\mathrm{S}^{1}$, BARI MA ${ }^{2}$, WAZIB A ${ }^{3}$, SALMA UMMA ${ }^{4}$, SHAHEDUZZAMAN AKM ${ }^{5}$, DAS PP ${ }^{6}$, HOSSAIN MS $^{7}$
}

\begin{abstract}
Background: The purpose of this study was to determine the morbidity pattern and health seeking behaviour among the rural elderly population.

Methods: This cross sectional study was conducted in six villages of Telihati union of Gazipur District from February to June 2013. Purposive sampling technique was used to collected data from 249 respondents, aged 60 years and above.

Results: The mean age of the respondents was 64.2 (SD \pm 5.6 ) years. About $70.3 \%$ of the respondents were male, majority (47\%) respondents were illiterate, 33.3\% earned less then ten thousand taka per month. About half (58.2\%) of the elderly were still working, among the currently not working respondents majority (49\%) were totally dependent. and only 52.6\% respondents belonged to joint family. Almost all (98.8\%) the respondents had some health problems; among these eye problems (81.7\%), musculo-skeletal disorders (66.3\%), gastrointestinal disorders (52.4\%) and sleeping problems (50.4\%) were predominant. Females suffered more from eye problems, musculoskeletal disorder, gastrointestinal disorder and sleeping problems. On the other hand, males suffered more from respiratory and genitorurinary problems. About $61 \%$ have a Government hospital or Community clinic nearby their residence, $70 \%$ were satisfied with available health care facilities and $72 \%$ was satisfied with treating doctors even then a greater part (35\%) was irregular for check-up. Majority (73.5\%) was regular about taking treatment, among the irregulars majority (77.3\%) was for un-affordability of medicine. Only 53\% of the elderly knew names of some old age diseases.
\end{abstract}

Key words: Morbidity pattern, health-seeking behavior, senior citizens.

J Dhaka Med Coll. 2013; 22(2) : 129-135.

\section{Introduction:}

The proportion of older persons has been raising steadily, from 7 per cent in 1950 to 11 per cent in 2007 , it is projected that, by 2020 , there will be one billion elderly persons (e"65 years) in the world, $71 \%$ of whom will live in low-income countries. ${ }^{1}$ The number of elderly persons in Bangladesh was projected to double from 7.8 million in 2001 to 16.2 million by $2025 .^{2}$ The country is currently undergoing both epidemiologic and demographic transitions, where the decline in both fertility and mortality rates in early life have resulted in increased life expectancy. According to the estimation of the United Nations, life expectancy at birth is expected to increase to 74 years in $2025 .{ }^{3}$ Based on data from Bangladesh, life expectancy at birth is expected to be 76.9 years for men and
85.1 years for women in 2015, calculated based on the scientific report of ICDDR, B. ${ }^{4}$ Chronic health conditions are common in elderly persons, and the prevalence of multiple chronic conditions is expected to increase ${ }^{5}$ Chronic diseases, by nature, will accumulate with ageing and present as multiple morbidities. Numerous studies have examined the distribution of multimorbidity among older persons in developed nations, ${ }^{6}$ but literature is scanty on multimorbidity among the elderly people in developing countries. In India, Joshi reported in 2003 that $83 \%$ of the elderly people had more than three morbidities. ${ }^{6}$ Research showed that average number of morbidities per person was 2.77 among the elderly people of rural India. ${ }^{7}$ In China, $21.7 \%$ of rural elderly people have at least two morbidities, and 15.9\%

1. Dr. Suraiya Jabeen, Assistant Professor, Department of Community Medicine, Dhaka Medical College, Dhaka

2. Dr. Mohammad Anwarul Bari, Assistant Professor, Dept. of Medicine, Sir Salimullah Medical College, Dhaka

3. Dr. Amit Wazib, Junior Consultant, Dhaka Medical College Hospital, Dhaka

4. Dr. Umma Salma, Assistant Professor Dept. of Medicine, National Medical College, Dhaka

5. Dr. AKM Shaheduzzaman, Assistant Professor Dept. of Medicine, Rangpur Medical College

6. Dr. Partho Protim Das, Associate Professor, Department of Medicine, Dhaka Medical College, Dhaka

7. Dr. Md. Sazzad Hossain, Assistant Professor, Department of Medicine, Gazipur Medical College

Correspondence : Dr. Suraiya Jabeen, Associate Professor, Department of Community Medicine, Dhaka Medical College, Dhaka 
have three or more morbidities. ${ }^{8}$ Little is known about the prevalence of morbidity among elderly persons in rural Bangladesh. Also, there is scanty information on the distribution of chronic conditions and multimorbidity by socioeconomic status. 9 The health and diseases of the elderly also requires attention by socioeconomic status. Health inequality by socioeconomic status present in both highincome and low-income countries. ${ }^{10}$ People with low socioeconomic status suffer from more diseases than those with higher socioeconomic status throughout their life span. As newborns, they suffer from health problems, such as premature birth, low birth weight and later on from chronic diseases, such as diabetes or heart disease. They also suffer from infectious diseases or disabilities, such as blindness. In short, the poor people suffer from more illhealth and die at a younger age compared to their better-off counterparts. ${ }^{10}$ The main purpose of this study was to determine the morbidity pattern and health seeking behaviour among the elderly people in rural Bangladesh.

\section{Methods:}

A cross-sectional study of morbidity pattern and health seeking behaviour of geriatric population in the rural area of Gazipur District, was planned in the field practice area of Department of Community Medicine, Dhaka Medical College, Dhaka. All elderly persons in the age group of 60 years and above were included in the study and after following inclusion and exclusion criteria data was collected from 249 individuals. The study was conducted from February to June 2013.Purposive sampling technique was followed. Data was collected by a pre-tested semi-structured questionnaire through face to face interview and limited physical examination by the fourth year MBBS students. Semi-structured Interview schedule contained two major sections. Section- A contained socio demographic part and section- B contained morbidity pattern and health seeking behaviour of the elderly population of some selected villages of Gazipur District. Clinical examination included a general physical examination. Height and Weight were taken, blood pressure measured, and if high BP detected in 1 st instance, two more readings were taken on different occasions to confirm hypertension. The purpose of the study was explained and confidentiality of the information was assured. Data were presented with mean and standard deviation for continuous variable and categorical variables were compared by chisquare statistics. Data were analyzed by using the SPSS version 17.0.

\section{Results}

Old age characterized by declining physical capacities, is usually associated with many diseases. For the purpose of the study, the health status and health seeking behaviour of the respondents was ascertained by asking questions about the extent of loss of vision, hearing and other health problems faced by them and the available healthcare facilities nearby, also about their attitude of taking the services. Table -I shows that a major fraction of the population was in the age group of 60-64 years old, while a small fraction $(6.5 \%)$ were 75 years old or older. Males $(70.3 \%)$ were more than the females. All most all respondents were $(99.6 \%)$ were Muslims. This reflects the true picture of the population based on religion at the local and national level. A joint family system was seen to be the most common (52.6 $\%)$ among the population interviewed followed by the nuclear family. Literacy was found to be low in the study population, majority $(47.4 \%)$ were illiterate. Among the currently not working respondents, majority $(78.8 \%$ were totally dependent, about $12.5 \%$ were partially dependent and rest $8.7 \%$ were totally independent. Chi-sq. test among gender and economic condition was significant $(p=.030)$

Among 249 elderly respondents, $35.7 \%$ were tobacco smokers, among them almost all (95.4 $\%$ were male and $64.3 \%$ were non-smokers among them majority were females. Chi-sq. test among gender and current tobacco smoking habit was highly significant $(\mathrm{p}<.001)$. Among 249 respondents $62.7 \%$ were current tobacco chewers and $37.3 \%$ non tobacco chewer. 
Table-I

Socio-demographic profile of the study population

\begin{tabular}{llccc}
\hline Variable & & Male (\%) & Female (\%) & Total (\%) \\
\hline Age group (years) & 60-64 yrs. & $107(61.1)$ & $43(58.1)$ & $150(60.2)$ \\
& 65-69 yrs. & $45(25.7)$ & $15(20.3)$ & $60(24.1)$ \\
& 70-74 yrs. & $13(7.4)$ & $10(13.5)$ & $23(9.2)$ \\
& $>75$ yrs & $10(5.8)$ & $6(8.1)$ & $16(6.5)$ \\
Gender & & $175(70.3)$ & $74(29.7)$ & $249(100.0)$ \\
Religion & Islam & $174(69.9)$ & $75(30.1)$ & $248(99.6)$ \\
& Hinduism & $1(0.4)$ & 0 & $1(0.4)$ \\
Education & Illiterate & $74(42.3)$ & $44(59.5)$ & $118(47.4)$ \\
& Informal & $19(10.9)$ & $11(14.9)$ & $30(12.0)$ \\
Occupation & Formal & $82(46.9)$ & $19(25.7)$ & $101(40.6)$ \\
& Work & $130(74.3)$ & $15(20.3)$ & $145(58.2)$ \\
Economic condition & Totally dependent & $31(25.7)$ & $59(79.7)$ & $104(41.8)$ \\
& Do not work & $10(22.2)$ & $31(86.4)$ & $82(78.8)$ \\
& Partially dependent & $4(8.9)$ & $5(8.5)$ & $9(8.7)$ \\
Family type & Totally independent & $86(49.1)$ & $32(43.2)$ & $118(47.4)$ \\
& Nuclear family & $89(50.9)$ & $42(56.8)$ & $131(52.6)$ \\
\hline
\end{tabular}

Almost all $(98.8 \%)$ respondents reported having illness. It is evident from Fig: I that the health status of women is poor compared to that of men. The majority $(81.7 \%)$ of the respondents had Eye problem, among them majority were female. About $26.4 \%$ of the respondents had hearing problems. However, more number of women compared to men reported difficulty in hearing. Other morbidities such as musculo-

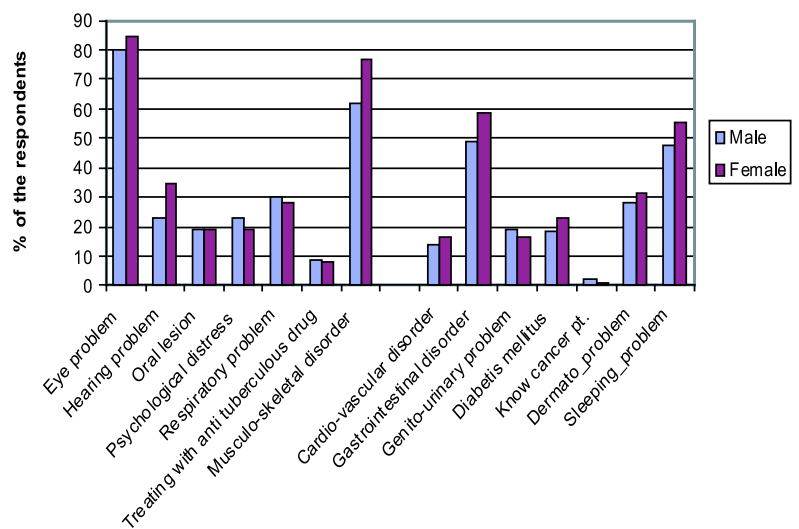

Fig.-1: Morbidity pattern of the elderly by their gender $(n=246)$ skeletal disorders (66.3\%), gastrointestinal disorder $(18.3 \%)$, diabetes mellitus $(19.5 \%)$, sleeping problems (50.4\%) dermatological problems $(29.3 \%)$ were also more common among women. On the other hand, problems such as respiratory problems and genitorurinary problems are prevalent more in males. But oral lesions, tuberculosis and cancers were found equally distributed.

Majority $(70.3 \%)$ of the respondents was satisfied and with available health care facilities. Table-2 showed that $70.3 \%$ respondents can do their daily activities without any difficulty, among them majority were male. $25.7 \%$ can do with difficulty and majority is female and only $4 \%$ cannot do without help, again females are more. Significant association was found $(\mathrm{p}=0.038)$.

Fig: II shows that majority (42.6\%) of them have a Government hospital, Community clinic $(18 \%)$, private practitioner $(15 \%)$ available nearby their residence. Distribution of the respondents by frequency of check-up showed 
Table-II

Distribution of the respondents by performance of daily activities by gender

\begin{tabular}{lccc}
\hline Perform Daily Activities & Gender & Percentage & \\
& Male (\%) & Female (\%) & Total \\
\hline Can do without any difficulty & $131(74.9)$ & $44(59.4)$ & $175(70.3)$ \\
Can do with difficulty & $37(21.1)$ & $27(36.5)$ & $64(25.7)$ \\
Cannot do without help & $7(4.0)$ & $3(4.1)$ & $10(4.0)$ \\
\hline Total & $175(100.0)$ & $74(100.0)$ & $249(100.0)$ \\
\hline
\end{tabular}

$*\left(\lambda^{2}=6.519, \mathrm{df}=2, \mathrm{p}=0.038\right)$

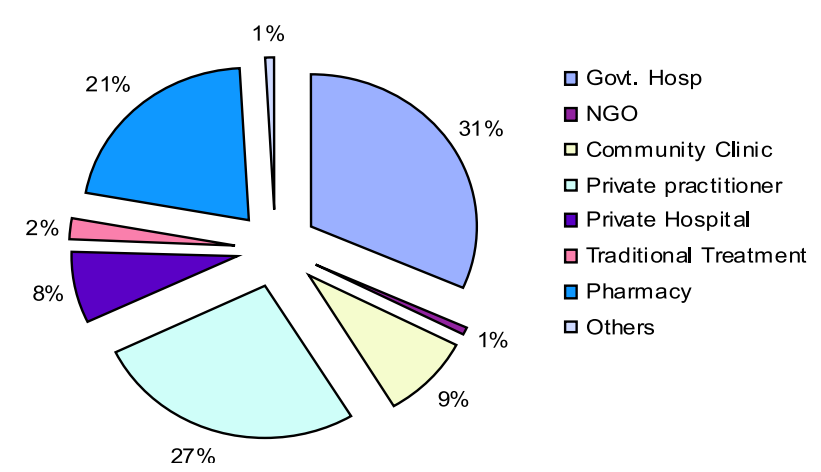

Fig.-2: Respondents by place of their treatment for illness

that majority (35\%) was irregular, $25 \%$ had checkup once in a year, and almost $19 \%$ did once in six months Majority (72\%) was satisfied with treating doctors and only $28 \%$ were not satisfied. About the regularity of taking prescribed treatment only $26.5 \%$ were irregular. The reasons for irregularity of taking prescribed treatment showed majority $(77.3 \%)$ said medicines are expensive, about $11 \%$ said they don't get them nearby $9 \%$ considered them

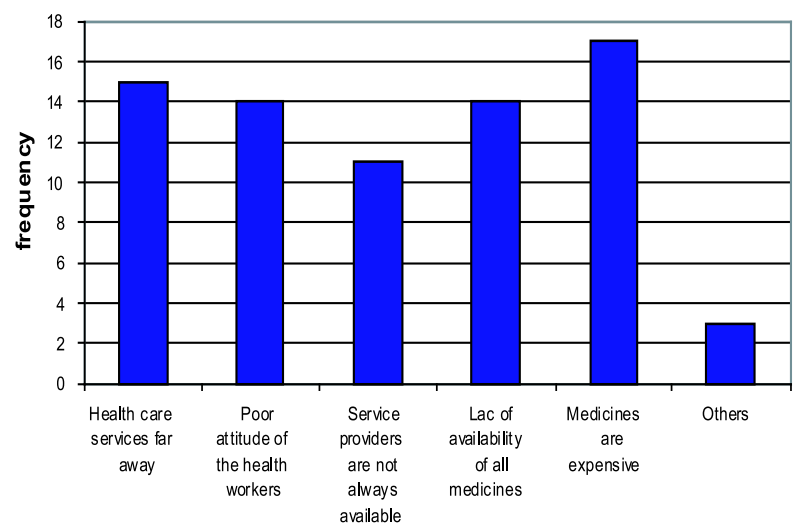

Fig.-3: Distribution of the respondents by reasons for not being satisfied with health services unnecessary. Distribution of the respondents by place of treatment for illness showed that majority (31 percent) preferred to go to Govt. hospitals, $27 \%$ to Private Practitioners and 21 $\%$ to pharmacy nearby.

Fig: III shows distribution of respondents by reasons for not being satisfied with health services, majority said medicine are expensive $(23 \%)$, health care services are far away $(20.3 \%)$,service providers not available $(20.9 \%)$ etc..

\section{Discussion:}

This study was done to find out the morbidity pattern and health seeking behaviour among the 249 senior citizens from Telihati union of Gazipur district. More then half of the respondents were from Mulaid and Tepirbari villages. Their mean age was $64.2(\mathrm{SD} \pm 5.6)$ years. Nearly two thirds belonged to 60-64 years age group. Almost three fourths of the respondents were male and majority was currently married. These findings do not accord with national statistics, as most of the data were collected from streets, shops and mosques etc. so there could be the predominance of male, young old senior citizens. ${ }^{2}$

Almost half of the respondents were illiterate, and more than half of the elderly were still at work. Among the currently not working respondents, majority were economically totally dependent on their family. About one third earned five to ten thousand taka per month. These findings accords with our national statistics. ${ }^{2}$ Half of the respondents belonged to joint family, having 4-6 family members. These findings accords with national statistics, where our average family member is seven. ${ }^{2}$ 
Among all the respondents, about one third was tobacco smokers; among them almost all were male. Out of which one fourth had been smoking tobacco for 31-40 years. Bangladesh is a conservative country where open smoking is still not appreciated for male and women who smokes never admits it in public. More then half of the respondents were current tobacco chewers among them one third had been chewing tobacco for 11-20 years. Not only in Bangladesh, but tobacco chewing is more prevalent in this subcontinent, so as oral cancer. The primary cause of very high incidence of oral cancer in South Asia is the widespread habit of chewing betel quid (or paan) and related areca nut use. ${ }^{11}$

Almost all (98.8\%) had one or more health problems. Gender wise differences were found in the health status of the elderly respondents. Compared to men, the health status of women was found to be poorer. This might be due to under nourishment associated with cultural practices in Bangladesh especially in rural areas. Women in rural areas, generally take meals only after their husbands and children have had their food. They contend with whatever that was left, which most of the time would not be sufficient diet for them. Moreover, the diseases specific to women and other natural biological processes, which the women may undergo, could be some of the reasons for the overall low health status of women.

In our study, the common morbidities found were eye problems, hearing problem, musculoskeletal disorder, cerebrovascular disorder, gastrointestinal disorder, diabetes, dermatological problem and sleeping problems were more common among females. On the other hand, problems such as respiratory and genitor-urinary were more prevalent in males. But oral lesions, tuberculosis and cancers were equally distributed. This study also accords with Manandhar et al. ${ }^{12}$ study, where they found $43 \%$ diabetic, $47.7 \%$ hypertensive, and $68.2 \%$ visually impaired; all these were higher in the 70-79 years age group.

In a study on the aged population in a rural area of Wardha district reported that the common morbidities were cataract $(30 \%)$, arthritis and arthralgia (15.6\%), refractory error $(13.6 \%)$, anemia (13.3\%), chronic bronchitis $(7.3 \%)$, dental caries $(7 \%)$, hypertension $(5.2 \%)$, which increased with increasing age to a maximum above the age of 65 years. ${ }^{13} \mathrm{~A}$ study from rural area of Rohtak district of Haryana, reported that the leading symptoms among the male elderly were visual impairment (65\%). ${ }^{14}$

In South Korea, life style-related diseases, including hypertension, arthritis, diabetes mellitus and osteoporosis, were the most common morbidities; most prevalent was hypertension $(37.5 \%)$, followed by diabetes mellitus $(14.9 \%){ }^{15}$

Experiences from geriatric clinics in Northern India revealed that hypertension was the most commonly reported physical diagnosis (50\%); other specific medical illnesses were osteoarthritis $(15 \%)$, diabetes $(13 \%)$ and constipation (8\%). ${ }^{14}$

Our study result accords with Khanam et. al. ${ }^{9}$, where they found morbidities was significantly higher among women, illiterates, persons who were single, and having low family income.

This study also accords with Jabeen et al., 16 where they found morbidity pattern of the elderly respondents attending BAAIGM were, arthritis $(27.9 \%)$, heart disease $(17.1 \%)$, chronic bronchitis $(16.2 \%)$, diabetes $(14.4 \%)$, peptic ulcer diseases (11.7\%) and rest urogenital and other diseases (12.7\%). Knowledge about old age diseases were limited to diabetes (57.9\%), high blood pressure (53.3\%), heart diseases $(50.4 \%)$, respiratory diseases $(31.8 \%)$, and orthopaedic diseases (3.7\%), and $41.1 \%$ had no knowledge about old aged diseases.

About two thirds of the respondents have Government health care facilities nearby rest one third have private practitioner nearby their residence. But their frequency of check-up showed that majority was irregular, even they were satisfied with their doctors. This result accords with Jabeen et al., study ${ }^{16}$, where they found most of the respondents $(81.7 \%)$ were not regular in health check-ups. Two thirds of them were regular in taking prescribed treatment; the rest one third was irregular due 
to the expense and unavailability of the drugs. Narapureddy et al., ${ }^{17}$ studied among the 411 elderly persons on their health seeking behaviour, they found $45.7 \%$ sought treatment from private practitioner and private hospital, $32.3 \%$ from non registered practitioner (Quack), only $18.9 \%$ sought treatment from Government hospital and remaining $3.1 \%$ used home remedies or sought help from traditional healers.

About $88.4 \%$ elderly performed physical activity, among them majority were male. With regard to the performance of day-to-day activities relating to personal care, dressing etc, it was reported that more male compared to female could able to perform these tasks without others help. Walking was under taken by $217(67 \%)$ as a physical exercise. ${ }^{18}$

Half of the respondents were familiar with old age diseases, majority knew about CVDs, diabetes, respiratory diseases and cataracts. This result accords with Jabeen et al., study, 16 where they found only $51.4 \%$ respondents could name some common geriatric diseases. Anemia was found among less then half of the respondents, where majority were female. Anemia was absent among majority of the males. Our study result does not similar with Manandhar et al. study ${ }^{12}$, where they found $86 \%$ respondents were anemic.

About one third of the respondents had SBP between $120-129 \mathrm{mmHg}$, only $10 \%$ have above $150 \mathrm{~mm} \mathrm{Hg}$. Almost all had DBP below $90 \mathrm{mmHg}$ and only 3 of them had e" $95 \mathrm{mmHg}$. Wilking et al. observed that the prevalence of isolated systolic hypertension appeared to be greater for women than for men; whereas the WHO reports a common prevalence of $56 \% .{ }^{19}$ Previous researchers in India reported a lesser magnitude of hypertension that ranged from 5.2 to $16.5 \% .{ }^{13}$ Anil Purty et al. reported $25.9 \%$ hypertension among the geriatric population. ${ }^{20}$

Majority (48\%) of the respondents had normal BMI, about $28 \%$ were underweight, and $14 \%$ were pre-obese and only $2 \%$ were grade 2 obese. Respondent's mean BMI was 22.50 ( $\mathrm{SD} \pm 3.6$ ). About $50 \%$ of the population had BMI $<18.5$. MNA revealed a prevalence of $26 \%$ for protein- energy malnutrition and $62 \%$ for risk of malnutrition. ${ }^{21}$

These findings highlight the needs for their periodic medical examination and treatment at the primary care level, which will help prevent further detoriation of their health status. Remarkable emphasis should be given to the health status of poor elderly women residing in rural areas of Bangladesh.

\section{Conclusion:}

The study has shown that the prevalence of morbidity is higher in rural areas of Gazipur district, especially among the elderly women. Emphasis should be given to the certain common specific factors that influence the health status among the elderly belonging to gender wise distribution. Hence, these findings raise a number of issues for formulating appropriate health policies for the elderly. There should be separate geriatric clinics in both private as well as government hospitals to deal with the problems faced by the elderly. Further studies in large scales are needed to explore the morbidity and health seeking behaviour of senior citizen of Bangladesh.

\section{Acknowledgement:}

We are grateful to the fourth year MBBS students (K-67) of Dhaka Medical College, Dhaka, for their full hearted support in data collection.

\section{References:}

1. Solomons NW. Health and ageing. In: Flores R, Gillepsie S, eds. Health and nutrition: emerging and reemerging issues in developing countries. Washington D.C.: International Food Policy Research Institute, 2001.

2. Bangladesh Bureau of Statistics, BBS. Statistical Pocketbook of Bangladesh 2001. Dhaka: Bangladesh Bureau of Statistics, Planning Division, Ministry of Planning, Government of the People's Republic of Bangladesh. 2002.

3. Population summary for Bangladesh international data base. Washington DC: US Census Bureau, 2010. (http://www.census.gov/population/ international/ data/idb/country.php accessed on 27 June 2011).

4. International Centre for Diarrhoeal Disease Research, Bangladesh. Health and demographic surveillance system-Matlab. V. 42. Registration 
of health and demographic events 2008. Dhaka: International Centre for Diarrhoeal Disease Research, Bangladesh; 2010. 71 p. (icddr,b scientific report no. 109).

5. Wolff JL, Starfield B, Anderson G. Prevalence, expenditures, and complications of multiple chronic conditions in the elderly. Arch Intern Med 2002; 162: 2269-76.

6. Joshi K, Kumar R, Avasthi A. Morbidity profile and its relationship with disability and psychological distress among elderly people in northern India. Int $\mathrm{J}$ Epidemiol 2003; 32: 97887.

7. Purty AJ, Bazroy J, Kar M, Vasudevan K, Veliath A, Panda P. Morbidity pattern among the elderly population in the rural area of Tamil Nadu, India. Turk J Med Sci 2006; 36: 45-50.

8. Zhou B, Chen K, Wang J, Wang H, Zhang S, Zheng W. Quality of life and related factors in the older rural and urban Chinese populations in Zhejiang province. J Appl Gerontol 2011; 30: 199225.

9. Khanam MA, Streatfield PK, Kabir ZN , Qiu C, Cornelius C, Åke Wahlin C. Prevalence and patterns of multimorbidity among elderly people in rural Bangladesh: a cross-sectional study. J Health Popul Nutr 2011; 29(4): 406-14

10. World Health Organization. Closing the gap in generation: health equity through action on the social determinants of health. Final report. Geneva: World Health Organization; 2008.

11. Balaram, P., et al., Oral cancer in southern India: the influence of smoking, drinking, paan-chewing and oral hygiene. Int $\mathrm{J}$ Cancer 2002. 98(3): p. 440-5.

12. Manandhar MC, Anklesaria PS, Ismail SJ. Weight, skinfolds and circumference characteristics of poor elderly people in Mumbai, India. Asia Pac J Clin Nutr 1997; 6: 191-9.
13. Kishore S, Garg BS. Sociomedical problems of aged population in a rural area of Wardha district. Indian J Public Health 1997; 41: 43-8.

14. Bharati D R, Pal R P, Rekha R, Yamuna T V, Kar S. Ageing in Puducherry, South India: An overview of morbidity profile. J Pharm Bioallied Sci 2011 ; 3(4): 537-42.

15. Woo EK, Han C, Jo SA, Park MK, Kim S, Kim E, et al. Morbidity and related factors among elderly people in South Korea: Results from the Ansan Geriatric (AGE) cohort study. BMC Public Health 2007; 7:10.

16. Jabeen S, Haque M A, Siddiqua SA, Hossain S, Jabber MA, Khan W. Self-health care among the elderly attending Bangladesh Institute of Geriatric Medicine, Dhaka. JOPSOM 2001; 20(1): 19-22.

17. Narapureddy B, Naveen KH, Madithati P, Singh RK, Pirabu RA. Socio-demographic Profile and Health Care Seeking Behaviour of Rural Geriatric Population of Allahabad District of UP: A Cross Sectional Study. Int J Med Sci Pub Health 2012; 1(2): 87-92.

18. Venkateswarlu V, Iyer RSR, Rao MK. Health status of the rural aged in Andhra Pradesh: a sociological perspective. HelpAge India: Res Dev J 2003; 9(2): 84-90.

19. Wilking SV, Belanger A, Kannel WB, D'Agostino RB, Steel K. Determinants of isolated systolic hypertension. JAMA 1988; 260: 3451-5.

20. Purty A J, Bazroy J, Malini KAR, Kavita V, Anita V, Purushottam P. Morbidity Pattern Among the Elderly Population in the Rural Area of Tamil Nadu, India. Turk J Med Sci 2006; 36 : 45-5.

21. Kabir ZN, Ferdous T, Cederholm T, Khanam MA , Streatfied K, Wahlin AK. Mini nutritional assessment of rural elderly people in Bangladesh: the impact of demographic, socio-economic and health factors. Pub Health Nutr 2006; 9(8): 96874 . 